\title{
Necessidade de ajustes no sistema de recomendação de calagem e adubação de oliveiras (Olea europaea L.) no sul do Brasil ${ }^{1}$
}

\author{
Darlize Déglan Borges Beulck Bender ${ }^{2}$; Mirla Andrade Weber ${ }^{3}$; Frederico Costa Beber Vieira ${ }^{4}$
}

\begin{abstract}
Resumo: O Rio Grande do Sul (RS) é o maior produtor de azeitonas do país com capacidade de aumentar a produção. No entanto, o sistema de recomendação de calagem e adubação precisa ser ajustado para a situação edafoclimática do estado. O objetivo deste estudo foi realizar um levantamento da condição nutricional de pomares de oliveira em produção, representativos da região central do RS, buscando identificar os principais aspectos que precisam ser melhorados no manejo da fertilidade. Em 13 pomares adultos localizados em Caçapava do Sul/RS e Cachoeira do Sul/RS, nos anos de 2016 e 2017, amostras de solo, folhas e frutos foram coletadas e submetidas a análises de N, P, K, B e parâmetros de acidez do solo. Observou-se que grande parte dos solos avaliados apresenta elevado teor de Al trocável na camada de $20-40 \mathrm{~cm}$, sugerindo a necessidade de incorporação mais profunda da calagem na implantação do pomar e/ou de elevar o pH da superfície para favorecer a correção em profundidade. Grande parte dos pomares apresentou concentração de $\mathrm{N}$ nas folhas acima do recomendado, o que é preocupante, uma vez que esse excesso promove maior crescimento vegetativo e suprime a floração. Para o P e o B, as discrepâncias entre os teores nas folhas e nos solos sugere que o nível crítico no solo não está ajustado à situação de clima e solo da região. O B foi o nutriente que mais limitou a produção de frutos dos pomares avaliados.
\end{abstract}

Palavras-chave: Fertilidade; Nível crítico; Diagnose nutricional.

\section{Adjustment requirements in the liming and fertilization recommendation system for olive trees}

\section{(Olea europaea L.) in south Brazil}

\begin{abstract}
Rio Grande do Sul (RS) is the largest producer of olives in the country and has potential to produce even more. However, the liming and fertilization recommendation system needs to be adjusted for the local soil and climate conditions. The objective of this study was to perform a survey of the nutritional status of olive orchards in production, representative of the central region of RS, seeking to identify the main aspects that need to be improved in the management of fertility. Soil, leaf and fruit samples were collected in 13 adult orchards located in Caçapava do Sul and Cachoeira do Sul/RS, in the years 2016 and 2017, and were submitted to analysis of N, P, K, B contents and soil acidity parameters. Most of the evaluated soils had a high content of $\mathrm{Al}$ exchangeable in the $20-40 \mathrm{~cm}$ layer, suggesting the need for deeper incorporation of lime on orchard implantation and/or raising the surface $\mathrm{pH}$ to favor depth correction. Most of the orchards had $\mathrm{N}$ content in the leaves above the recommended one, which is worrying, since the excess of $\mathrm{N}$ in the tissue promotes greater vegetative growth and suppresses the flowering. For $\mathrm{P}$ and $\mathrm{B}$, discrepancies between leaf and soil levels suggest that the critical soil level is not adjusted to the climate and soil conditions of the region. B was the most restrictive nutrient to fruit yield in the evaluated orchards.
\end{abstract}

Keywords: Fertility; Threshold value; Nutritional diagnosis.

\footnotetext{
${ }^{1}$ Recebido em 09.02.2018 e aceito para publicação como artigo científico em 28.06.2018.

${ }^{2}$ Bióloga, M.sc. E-mail: <darlizebender@gmail.com>.

${ }^{3}$ Agrônoma, Dra. Professora Adjunta da Universidade Federal do Pampa, Câmpus São Gabriel. E-mail: <mirlaweber@ unipampa.edu.br>.

${ }^{4}$ Agrônomo, Dr. Professor Associado da Universidade Federal do Pampa, Câmpus São Gabriel. E-mail: <fredericovieira@unipampa.edu.br>.
} 


\section{Introdução}

A cultura da oliveira é milenar sendo tradicionalmente estudada e explorada nos países do Mediterrâneo, de onde se expande continuamente por todos os continentes devido ao grande interesse econômico de produção, venda e consumo (SILVA, 2013). O Brasil é um dos 10 países que mais importam e consomem o azeite no mundo (OLIVA, 2016).

Atualmente entidades governamentais incentivam o cultivo de oliveiras no Brasil, principalmente através do pequeno agricultor, por considerar a importância que essas plantas e seus produtos oferecem. O Rio Grande do Sul é considerado o maior produtor de oliveiras do Brasil onde, atualmente, existem 160 produtores em um total de 2,1 mil ha cultivados em 55 municípios, com oito indústrias e dezessete marcas de azeite de oliva extra virgem (ADAMI, 2017). O estado apresenta potencial para grande expansão da cultura (ALBA et al., 2014), porém a viabilidade disto depende da geração de conhecimento em diversos aspectos. Dentre eles, a área que ainda apresenta grande lacuna de conhecimento é a de calagem e adubação de oliveiras.

Por ser uma cultura com expansão comercial recente no Brasil, os olivicultores utilizam, principalmente, recomendações de adubação e calagem que, embora sejam publicações nacionais, foram elaboradas sob forte influência dos resultados de pesquisa obtidos em outros países, onde as condições de clima e solo são muito distintas às do sul do Brasil (CQFS RS/SC, 2016; EPAMIG, 2012). Destaca-se, principalmente, resultados de experimentos realizados nos países da região mediterrânea e na Califórnia/EUA, onde há maior escassez de água e solos calcários são comuns. Nas duas bibliografias supracitadas, as classes de valores para a interpretação dos teores de macro e micronutrientes nas folhas de oliveiras no Brasil são baseadas, principalmente, em estudos realizados por Freeman et al. (2005), Chapman (1996), Beutel et al. (1983) e por Childers (1966), devido, essencialmente, à escassez de trabalhos de pesquisa nacionais e regionais com a cultura da oliveira.

Apesar da cultura ter evoluído no Brasil, fazse necessário verificar se esses critérios utilizados são ajustados para as condições de solo e clima do sul do país, visto que, até o momento, não existe a determinação dos valores críticos de nutrientes no tecido foliar e do solo que limitariam a produção no contexto local. A necessidade nutricional das oliveiras é afetada pelo clima local, especialmente pela temperatura, índice pluviométrico e umidade do solo, fazendo com que haja a necessidade de que o sistema de recomendação de adubação e calagem sejam ajustados conforme a condição de solo e de clima de cada região. Com isso, consegue-se fornecer uma fertilização mais adequada de acordo com as reais necessidades e com o potencial de resposta da planta, maximizando a produção, a eficiência de uso dos insumos e minimizando riscos de contaminação do ambiente pelo excesso de fertilização (PAULUS, 2011).

$\mathrm{O}$ ajuste de um sistema de recomendação passa por duas etapas sequenciais: estudos de correlação e estudos de calibração de doses (CANTARUTTI et al., 2007). Os estudos de correlação determinam qual é a relação entre o crescimento/produção da cultura com a quantidade de nutrientes disponíveis no solo ou com a concentração de nutrientes no tecido foliar; nesta etapa é que são delimitados os níveis críticos e as classes de interpretação de cada nutriente. Esses dados servem como passo inicial para os estudos de calibração de dose de fertilizantes, que por sua vez, são a essência do ajuste do sistema de recomendação de fertilizantes para a cultura de oliveiras às situações de solo e clima do local. O presente projeto se insere, portanto, na primeira etapa, através de correlações entre produção de azeitonas e teor de nutrientes no solo e no tecido foliar, onde a determinação dos níveis críticos, obtidos através de estudos de correlação, servirá para verificar quais nutrientes são mais limitantes à produção de azeitonas nos pomares avaliados.

Neste sentido, o presente estudo tem por objetivo realizar um levantamento do estado 
nutricional de pomares de oliveira em produção, representativos da região central do RS, buscando avaliar as principais limitações químicas e os principais aspectos que precisam ser aprimorados no sistema de recomendação de calagem e adubação para a cultura.

\section{Material e métodos}

Caracterização da região e dos pomares

O estudo foi realizado em 13 pomares de oliveiras da variedade Arbequina, localizados nos municípios de Caçapava do Sul e Cachoeira do Sul. Essa área é classificada como recomendável ao cultivo da cultura no RS pelo zoneamento agroclimático (ALBA et al., 2014). Cachoeira do Sul caracteriza-se como clima do tipo Cfa subtropical segundo a classificação de Koppen. Apresenta precipitação média anual de aproximadamente $1.416 \mathrm{~mm}$, com chuvas durante todos os meses do ano, e temperatura superior a $22^{\circ} \mathrm{C}$ (verão quente) no mês mais quente e superior a $3{ }^{\circ} \mathrm{C}$ no mês mais frio. Em Caçapava do Sul predomina o clima do tipo $\mathrm{Cfb}$ subtropical com precipitação média anual de aproximadamente $1.538 \mathrm{~mm}$. Caracterizam-se ambas com verão ameno, com temperatura média do ar inferior a $22^{\circ} \mathrm{C}$ no mês mais quente e a do mês mais frio superior a $3{ }^{\circ} \mathrm{C}$ (CLIMATEDATA, 2017; SEMA, 2003). É importante ressaltar que, na época de floração e polinização no ano agrícola avaliado houveram vários dias consecutivos de chuva e a precipitação mensal foi maior que os anos normais (dados não demonstrados), o que pode ter diminuído a produção de frutos.

As principais características dos 13 pomares de oliveiras estudados estão apresentadas na Tabela 1. Em todos os pomares, as árvores foram provenientes de mudas reproduzidas por estaquia, em tubetes. O revolvimento do solo dos pomares foi realizado na área total, após aplicação de calagem. A aplicação de calcário foi, em média, de quatro toneladas por hectare na implantação, sendo que a maioria dos pomares recebeu reaplicação a cada dois anos. Em todos os pomares, houve aplicação de fertilizantes com $\mathrm{N}, \mathrm{P}$ e $\mathrm{K}$ na cova no plantio, enquanto a adubação de manutenção foi realizada anualmente na projeção da copa, em quantidades variáveis conforme as análises de solo e de tecido foliar. Maiores detalhes sobre os pomares e seus manejos podem ser obtidos em Bender (2018).

Coleta das amostras de solo, folha e frutos

As coletas de amostras de solo e de tecido foliar foram realizadas em julho e agosto de 2016, em oliveiras de variedade Arbequina cultivadas a campo. Primeiramente foram selecionadas e demarcadas geograficamente cinco árvores representativas de cada pomar selecionado. Em seguida, para cada oliveira, amostras de solo foram tomadas a um metro do tronco, nos quatro pontos cardeais e nas camadas de 0 a 20 e 20 a $40 \mathrm{~cm}$ de profundidade, totalizando, portanto, oito subamostras por árvore. $\mathrm{Na}$ sequência, as subamostras foram homogeneizadas para se obter uma amostra composta por árvore e por profundidade. Após a homogeneização, as amostras de solo foram secas ao ar, moídas e peneiradas $(2 \mathrm{~mm})$ para posteriores análises químicas. Nas mesmas árvores, para a análise do tecido foliar, foram coletadas 100 folhas por planta, recém-maduras, em todas as faces da copa, na parte central dos ramos do ano, localizados na altura do terço médio da copa. As amostras foram lavadas com água destilada, secas a $65^{\circ} \mathrm{C}$ até peso constante e moídas a $1 \mathrm{~mm}$, para posteriores análises químicas.

Em fevereiro de 2017, nas árvores onde havia sido realizada as coletas acima descritas, realizou-se a colheita manual de todos os frutos. A massa de frutos de cada árvore foi quantificada e foram separados 50 frutos por árvore para posteriores análises químicas. Após a lavagem com água destilada, os frutos foram secos a $65^{\circ} \mathrm{C}$ até peso constante. Em seguida, foram moídos manualmente, através de martelo e almofariz/pistilo de ágata, e armazenados sob refrigeração até a realização das análises de acordo com Tedesco et al. (1995). 
Tabela 1 - Localização dos pomares avaliados e descrição dos respectivos tipos de solo, idades do plantio, áreas de cultivo, espaçamentos entre árvores e uso anterior do solo.

Table 1 - Location of the investigated orchards, with their soil types, tree age, area, plant arrangements and ancient use of the soil.

\begin{tabular}{|c|c|c|c|c|c|c|}
\hline Pomar & Coordenadas & Tipo de solo* & Idade do plantio & Área (ha) & Espaçamento (mxm) & Histórico da área \\
\hline 1 & $\begin{array}{l}30^{\circ} 39^{\prime} 39.38^{\prime \prime S} \\
53^{\circ} 27^{\prime} 35.64^{\prime \prime O}\end{array}$ & Regosol & 12 anos & 1,8 & $5 \times 4$ & Campo nativo \\
\hline 2 & $\begin{array}{l}30^{\circ} 39^{\prime} 38.09^{\prime \prime} \mathrm{S} \\
53^{\circ} 27^{\prime} 40.78^{\prime \prime} \mathrm{O}\end{array}$ & Mollisol & 12 anos & 2,0 & $7 \times 5$ & Campo nativo \\
\hline 3 & $\begin{array}{l}30^{\circ} 33^{\prime} 44.78^{\prime \prime} \mathrm{S} \\
53^{\circ} 24^{\prime} 14.42^{\prime \prime} \mathrm{O}\end{array}$ & Acrisol & 9 anos & 1,0 & $3 \times 4$ & Campo nativo \\
\hline 4 & $\begin{array}{c}30^{\circ} 33^{\prime} 28.54^{\prime \prime S} \\
53^{\circ} 24^{\prime} 8.99^{\prime \prime O}\end{array}$ & Regosol & 9 anos & 2,0 & $3 \times 4$ & Campo nativo \\
\hline 5 & $\begin{array}{l}30^{\circ} 37^{\prime} 32.96 " \mathrm{~S} \\
53^{\circ} 20^{\prime} 41.04^{\prime \prime O}\end{array}$ & Regosol & 11 anos & 5,0 & $7 \times 6$ & Campo nativo \\
\hline 6 & $\begin{array}{l}30^{\circ} 23^{\prime} 56.99^{\prime \prime} \mathrm{S} \\
53^{\circ} 25^{\prime} 34.70^{\prime \prime} \mathrm{O}\end{array}$ & Regosol & 9 anos & 2,0 & $4 \times 5$ & Campo nativo \\
\hline 7 & $\begin{array}{l}30^{\circ} 22^{\prime} 22.92^{\prime \prime} \mathrm{S} \\
53^{\circ} 28^{\prime} 58.34 " \mathrm{O}\end{array}$ & Regosol & 8 anos & 5,2 & $4 \times 5$ & Campo nativo \\
\hline 8 & $\begin{array}{l}30^{\circ} 24^{\prime} 53.95^{\prime \prime} \mathrm{S} \\
53^{\circ} 26^{\prime} 48.62^{\prime \prime} \mathrm{O}\end{array}$ & Regosol & 9 anos & 4,5 & $5 \times 3$ & Campo nativo \\
\hline 9 & $\begin{array}{l}29^{\circ} 55^{\prime} 29.78^{\prime \prime} \mathrm{S} \\
52^{\circ} 54^{\prime} 34.40^{\prime \prime} \mathrm{O}\end{array}$ & Acrisol & 10 anos & 1,5 & $8 \times 5$ & $\begin{array}{l}\text { Plantação de soja e } \\
\text { criação de ovelhas }\end{array}$ \\
\hline 10 & $\begin{array}{l}29^{\circ} 55^{\prime} 29.78^{\prime \prime} \mathrm{S} \\
52^{\circ} 54^{\prime} 34.40^{\prime \prime} \mathrm{O}\end{array}$ & Acrisol & 10 anos & 1,5 & $8 \times 5$ & $\begin{array}{l}\text { Plantação de soja e } \\
\text { criação de ovelhas }\end{array}$ \\
\hline 11 & $\begin{array}{l}29^{\circ} 55^{\prime} 26.65^{\prime \prime} \mathrm{S} \\
52^{\circ} 54^{\prime} 25.10^{\prime \prime} \mathrm{O}\end{array}$ & Acrisol & 10 anos & 1,5 & $5 \times 4$ & $\begin{array}{l}\text { Plantação de soja e } \\
\text { criação de ovelhas }\end{array}$ \\
\hline 12 & $\begin{array}{l}29^{\circ} 55^{\prime} 27.03^{\prime \prime S} \\
52^{\circ} 54^{\prime} 25.92^{\prime \prime} \mathrm{O}\end{array}$ & Acrisol & 10 anos & 4,0 & $5 \times 4$ & $\begin{array}{l}\text { Plantação de soja e } \\
\text { criação de ovelhas }\end{array}$ \\
\hline 13 & $\begin{array}{l}29^{\circ} 55^{\prime} 32.63^{\prime \prime S} \\
52^{\circ} 54^{\prime} 35.16^{\prime \prime} \mathrm{O}\end{array}$ & Acrisol & 10 anos & 2,0 & $7 \times 6$ & $\begin{array}{l}\text { Plantação de soja e } \\
\text { criação de ovelhas }\end{array}$ \\
\hline
\end{tabular}

* Classificação pelo sistema da World Resource Base-FAO (WRB, 2006); os solos Acrisol, Mollisol e Regosol dos pomares equivalem, respectivamente, ao Argissolo Vermelho-amarelo distrófico, Chernossolo Ebânico Órtico e Neossolo Regolítico pelo Sistema Brasileiro de Classificação de Solos (SiBCS, 2014).

Análise química das amostras de solo, folha e fruto

As amostras de solo, de tecido foliar e de frutos foram quimicamente analisadas utilizando métodos descritos por Tedesco et al. (1995). No solo foram determinados o $\mathrm{pH}-\mathrm{H}_{2} \mathrm{O}(2: 1)$ e os teores de $\mathrm{Al}$ trocável, $\mathrm{B}, \mathrm{N}$ total, $\mathrm{P}$ e $\mathrm{K}$ trocáveis. $\mathrm{O} \mathrm{pH}-\mathrm{H}_{2} \mathrm{O}$ foi determinado por potenciometria; o Al foi extraído por solução $\mathrm{KCl} 1 \mathrm{M}$ e determinado por titulometria; $\mathrm{B}$ foi extraído pelo método da água quente, com $\mathrm{CaCl}_{2} 5 \mathrm{mmol} \mathrm{L}^{-1}$ conforme adaptação de Reis et al. (2006) e determinado por espectrofotometria; $\mathrm{N}$ foi determinado por digestão úmida, seguido de destilação de arraste a vapor semi-microKjeldahl; P e K trocáveis foram extraídos pela solução Mehlich $1 \quad\left(\mathrm{HCl}+\mathrm{H}_{2} \mathrm{SO}_{4}\right) \quad$ com determinações por espectrofotometria para $\mathrm{P}$ e fotometria de chama para $\mathrm{K}$.

No tecido foliar e no fruto foram determinados os teores de $\mathrm{N}$ total, $\mathrm{P}$ e $\mathrm{K}$, após digestão úmida das amostras. $\mathrm{O} \mathrm{N}$ foi determinado por destilação de arraste a vapor semi-micro-Kjeldahl; P por espectrofotometria; $\mathrm{K}$ por fotometria de chama. Os teores de $\mathrm{B}$ no tecido foliar e frutos foram determinados nas cinzas após queima em mufla $\left(600{ }^{\circ} \mathrm{C}\right.$ por duas horas), extraído com $\mathrm{H}_{2} \mathrm{SO}_{4} \quad 0,18 \mathrm{M}$ e determinado por espectrofotometria.

Classes de valores para interpretação da composição química de macro e micronutrientes no solo, tecido vegetal e fruto da oliveira

As amostras de tecido vegetal foram 
classificadas de acordo com as tabelas de recomendação do Manual de Calagem e Adubação para os estados do RS e SC (CQFS RS/SC, 2016) e da EPAMIG (2012) (Tabela 2).

As amostras de solo também foram classificadas de acordo com as tabelas de recomendação do Manual de Calagem e Adubação (CQFS - RS/SC, 2016), conforme a Tabela 3. A média geral de nutrientes nos frutos em cada pomar foi comparada com os resultados dos estudos de El-Fouly et al. (2012) e Rodrigues et al. (2012).

Tabela 2 - Interpretação do teor de nutrientes nos tecidos vegetais das oliveiras.

Table 2 - Interpretation of nutrient concentrations in the leave tissues of olive trees.

\begin{tabular}{ccccc}
\hline Elementos & Insuficiente & Normal & Alto & Tóxico \\
\hline Nitrogênio $(\% \mathrm{~m} / \mathrm{m})$ & $<1,5$ & $1,5-2,0$ & $>2,0$ & - \\
Fósforo $(\% \mathrm{~m} / \mathrm{m})$ & $<0,1$ & $0,1-0,3$ & $>0,3$ & - \\
Potássio $(\% \mathrm{~m} / \mathrm{m})$ & $<0,8$ & $0,8-1,2$ & $>1,2$ & - \\
Boro $\left(\mathrm{mg} \mathrm{kg}^{-1}\right)$ & $<19$ & $19-150$ & $150-185$ & $>185$ \\
\hline
\end{tabular}

Tabela 3 - Classe de valores para interpretação do teor de nutrientes nos solos das oliveiras.

Table 3 - Class of values for interpretation of nutrient contents in soils of olive trees.

\begin{tabular}{|c|c|c|c|c|c|}
\hline \multirow{2}{*}{ Elementos } & Muito baixo & Baixo & Médio & Alto & Muito alto \\
\hline & \multicolumn{5}{|c|}{ 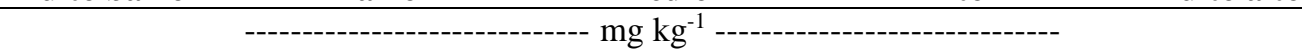 } \\
\hline Fósforo $(\mathrm{P})^{1}$ & $<6,0$ & $6,1-12,0$ & $12,1-18,0$ & $18,1-36,0$ & $>36,0$ \\
\hline Fósforo $(\mathrm{P})^{2}$ & $<10,0$ & $10,1-20,0$ & $20,1-30,0$ & $30,1-60,0$ & $>60,0$ \\
\hline Potássio $(\mathrm{K})^{3}$ & $0-30$ & $31-60$ & $61-90$ & $91-180$ & $>180$ \\
\hline Boro (B) & - & $<0,1$ & $0,1-0,3$ & $>0,3$ & - \\
\hline
\end{tabular}

${ }^{1}$ Classe textural 3: 21 a $40 \%$ argila; ${ }^{2}$ Classe textural 4: $<20 \%$ argila $;{ }^{3}$ Espécies classificadas no grupo 2 (frutíferas) e solo com CTC $\mathrm{pH}_{\mathrm{pH}, 0}$ : 7,6 a $15,0 \mathrm{cmol}_{\mathrm{c}} \mathrm{dm}^{-3}$.

Determinação do nível crítico

A determinação do nível crítico no solo foi realizada pelo procedimento de Cantarutti et al. (2007), em que os teores de nutrientes do solo foram correlacionados com o rendimento relativo (RR), organizados em um par de eixos cartesianos x e y, respectivamente (Figura 1). No gráfico, são traçadas duas linhas transversais, definindo os 4 quadrantes. A linha horizontal é fixada no valor de rendimento relativo que proporcione maior retorno econômico (assumido aqui como 90\%). Para os atributos cujos baixos teores impliquem em limitação do crescimento (como o teor de um determinado nutriente no solo, por exemplo), a linha vertical é alocada de forma que o somatório do número de pontos nos quadrantes II e IV (Figura 1A) seja o menor possível. Para os atributos cujos altos teores impliquem em limitação no crescimento (por exemplo, o teor de $\mathrm{Al}^{3+}$ do solo), a linha vertical é alocada de forma que o somatório do número de pontos nos quadrantes I e III (Figura 1B) seja o menor possível.

A determinação do nível crítico foi realizada somente para o teor de boro do solo, pois este foi o único nutriente que apresentou correlação significativa com o rendimento relativo dos frutos (Tabela 6). Em cada pomar, à árvore que obteve maior produtividade de azeitonas, dentre as cinco árvores selecionadas, foi atribuído o valor de $100 \%$ de produção relativa, enquanto que para as produções relativas das outras quatro árvores, do mesmo pomar, foram calculadas proporcionalmente a esta primeira. Assim, utilizando valores relativos é possível juntar vários pomares para o gráfico na estimativa do nível crítico do nutriente.

Análise estatística dos dados

As relações entre os atributos químicos do solo, tecido foliar, fruto e a produtividade de frutos foram avaliadas pela correlação de Pearson $(\mathrm{P}<0,10)$. 

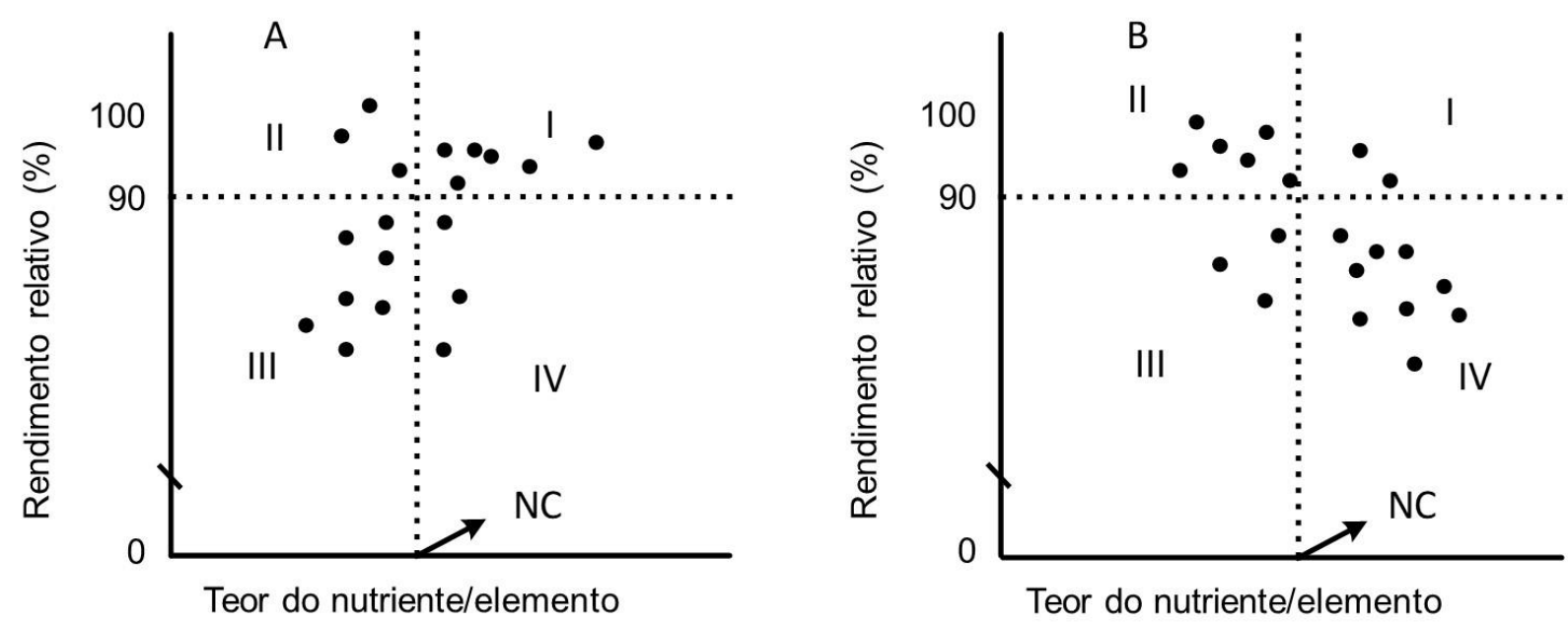

Figura 1 - Modelo esquemático para a determinação do nível crítico (NC). O teor do nutriente/elemento (eixo X) a ser utilizado pode ser a concentração do mesmo disponível no solo ou no tecido vegetal. Os gráficos A e B representam, respectivamente, atributos químicos que são benéficos e prejudiciais ao rendimento relativo em questão.

Figure 1 - Schematic model for determining the threshold value (NC). The content of nutrient/element (X axis) can be its concentration in the soil or in the plant tissue. Graphs A and B exemplify, respectively, benefic and injurious chemical attributes to the relative yield.

\section{Resultados e Discussão}

pH e Alumínio trocável do solo

A maioria dos solos avaliados apresentou parâmetros de acidez adequados para o crescimento das raízes da camada superficial de 0 a $20 \mathrm{~cm}$, já que mais de $90 \%$ dos solos desta camada estão com $\mathrm{pH}-\mathrm{H}_{2} \mathrm{O}$ superior a 5,5 e não apresentam Al trocável ( $\mathrm{Al}^{3+}$; Tabela 4$)$.

Tabela 4 - Distribuição relativa do pH do solo e dos teores de alumínio trocável nos solos das oliveiras.

Table 4 - Relative distribution of soil pH and exchangeable aluminum in the soil samples of the olive trees.

\begin{tabular}{|c|c|c|c|}
\hline \multirow{3}{*}{ Atributo } & \multirow{3}{*}{ Faixa de valor } & \multicolumn{2}{|c|}{ Profundidade $(\mathrm{cm})$} \\
\hline & & 0 a 20 & 20 a 40 \\
\hline & & \multicolumn{2}{|c|}{$\ldots \ldots \ldots$} \\
\hline \multirow{4}{*}{$\mathrm{pH}-\mathrm{H}_{2} \mathrm{O}$} & $<5,5$ & 8 & 58 \\
\hline & 5,6 a 6,0 & 22 & 8 \\
\hline & 6,1 a 6,5 & 24 & 3 \\
\hline & $>6,5$ & 46 & 31 \\
\hline \multirow{3}{*}{$\begin{array}{l}\text { Al trocável } \\
\left(\mathrm{cmol}_{\mathrm{c}} \mathrm{kg}^{-1}\right)\end{array}$} & $>1$ & 0 & 44 \\
\hline & 0,1 a 1,0 & 9 & 25 \\
\hline & 0 & 91 & 31 \\
\hline
\end{tabular}

Quase metade dos solos da camada de 0-20 $\mathrm{cm}(46 \%)$ apresentaram $\mathrm{pH}$ maior que 6,5. Logo, uma amostragem apenas nesta camada sugeriria ao produtor que a situação de acidez está favorável às plantas. No entanto, grande parte dos solos avaliados (44\%) apresentou elevado teor de $\mathrm{Al}^{3+}\left(>1 \mathrm{cmol}_{\mathrm{c}} \mathrm{kg}^{-1}\right)$ no subsolo, o que pode limitar o desenvolvimento das plantas tanto pela toxidez por $\mathrm{Al}^{3+}$ quanto por reduzir a disponibilidade dos nutrientes para as plantas (COUTINHO et al., 2009), dificultando a expansão do sistema radicular das oliveiras nas camadas mais profundas.

Cabe destacar que há uma certa relação direta e significativa $\left(\mathrm{R}^{2}=0,871, \mathrm{P}<0,001\right.$; dados não demonstrados) entre o $\mathrm{pH}$ das camadas mais profundas com as mais superficiais. Os solos que apresentaram $\mathrm{pH} \geq 6,5$ na superfície $(0$ a $20 \mathrm{~cm}$; 
$46 \%$ ) também apresentaram $\mathrm{pH} \geq 5,5$ na camada de 20 a $40 \mathrm{~cm}$ (42\%), o que evitaria, teoricamente, problemas de toxidez por $\mathrm{Al}^{3+}$ até a profundidade de $40 \mathrm{~cm}$ (Tabela 4). Considerando que, não se pode incorporar o calcário nos solos dos pomares adultos para não danificar as raízes, uma alternativa para diminuir o potencial de toxidez por $\mathrm{Al}^{3+}$ em subsolo é de elevar o $\mathrm{pH}$ da camada superficial a valores próximos a 6,5, pois isso favoreceria a descida da frente de alcalinização no perfil do solo, corrigindo o subsolo ao passar do tempo (RHEINHEIMER et al., 2000a).

Sabe-se que, nos países do Mediterrâneo, a cultura de oliveira se desenvolve em solos que apresentam naturalmente $\mathrm{pH}$ neutro a alcalino $(\geq$ 7). No entanto, no Brasil, os solos são naturalmente ácidos ( $\mathrm{pH}$ natural 4,5 a 5,5) (COUTINHO et al., 2009). A elevação do pH do solo a valores neutros pode não ser benéfica a algumas culturas devido ao risco da supercalagem e de restrições à nutrição da planta por deficiência de micronutrientes (SILVA et al, 2006). Portanto, o ajuste de recomendação de calagem para oliveiras deve considerar este risco, aliado ao retorno econômico da correção do $\mathrm{pH}$ em camadas de subsolo. Destaca-se que este tema deve ser melhor estudado em pesquisas futuras.

Teores de Nitrogênio, Fósforo, Potássio e Boro em amostras de solo, folha e fruto

\section{Nitrogênio}

Apenas 14\% dos pomares apresentaram teor

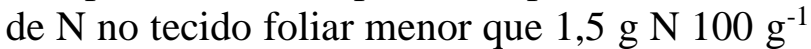
$\mathrm{MS}$, considerado limitante à produção de frutos pela oliveira. Porém, mesmo com baixo teor de M.O. no solo, uma grande proporção de pomares (58\%) manifestou níveis altos deste nutriente no tecido foliar (Tabela 5). Aparentemente há mais problemas para a produção se o teor de $\mathrm{N}$ estiver alto (> 2,0 g N $100 \mathrm{~g}^{-1} \mathrm{MS}$ ) no tecido do que se estiver baixo (< 1,5 g $\left.\quad \mathrm{N} \quad 100 \quad \mathrm{~g}^{-1} \quad \mathrm{MS}\right)$ (FERNÁNDEZ-ESCOBAR et al., 2009). O excesso de $\mathrm{N}$ no tecido promove o crescimento vegetativo acentuado e suprime a floração e produção de frutos, além de aumentar a frequência de podas.

Embora o teor de $\mathrm{N}$ no tecido foliar seja considerado adequado quando está entre 1,5 e 2,0 g N $100 \mathrm{~g}^{-1}$ MS (EPAMIG, 2012), alguns estudos apontam que oliveiras com teores de $\mathrm{N}$ maiores que $1,7 \mathrm{~g} \mathrm{~N} 100 \mathrm{~g}^{-1} \mathrm{MS}$ já exibiram menos inflorescências e menores quantidades de frutos (EREL et al, 2008), bem como a redução na longevidade dos óvulos (FERNANDEZESCOBAR et al., 2008). Com alto teor de $\mathrm{N}$ no tecido foliar, a oliveira também pode apresentar maior sensibilidade a geadas, ataque de pragas e desordens fisiológicas que afetam negativamente a produção e a qualidade dos frutos (EPAMIG, 2012). O teor de $\mathrm{N}$ no tecido foliar foi refletido em um maior teor deste nutriente no fruto das oliveiras do que em outros estudos encontrados. $\mathrm{O}$ teor médio de $\mathrm{N}$ encontrado nos frutos do presente estudo foi de

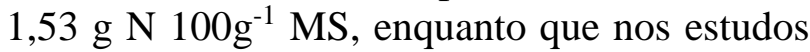
de Rodrigues et al. (2012) e El-Fouly et al. (2012) o teor variou de 0,09 a $0,47{\mathrm{~g} \mathrm{~N} 100 \mathrm{~g}^{-1}}^{-}$ MS, ou seja, bem abaixo do verificado no presente estudo.

Os solos apresentaram baixos teores $(\leq 2,5 \%)$ de M.O. em 64\% das amostras. Pode-se pressupor que a adubação nitrogenada mineral, portanto, seja o principal suprimento deste nutriente às plantas avaliadas. Neste caso, o excesso de $\mathrm{N}$ é um problema relativamente fácil de ajustar através do monitoramento frequente do tecido foliar e da aplicação de fertilizante em doses mais parcimoniosas, principalmente nos solos com elevado teor de MO, já que esta afeta diretamente a disponibilização do $\mathrm{N}$ pelo solo e o ajuste da dose de fertilizantes nitrogenado necessários. Assim, maiores doses devem ser aplicadas somente quando as concentrações de $\mathrm{N}$ na folha se apresentarem insuficientes $(<1,4 \%)$, a fim de otimizar a eficiência de uso do insumo, além de diminuir os danos na produção e possível poluição ambiental pelas perdas de $\mathrm{N}$ (VOSSEN, 2007; FREEMAN et al., 2005). 
Tabela 5 - Distribuição percentual das amostras de solo e de tecido foliar de oliveira nas classes de interpretação dos teores de N, P, K e B dos pomares avaliados.

Table 5 - Relative distribution of soil samples and olive leaf tissue samples in classes of interpretation of the N, P, K and B contents of the evaluated orchards.

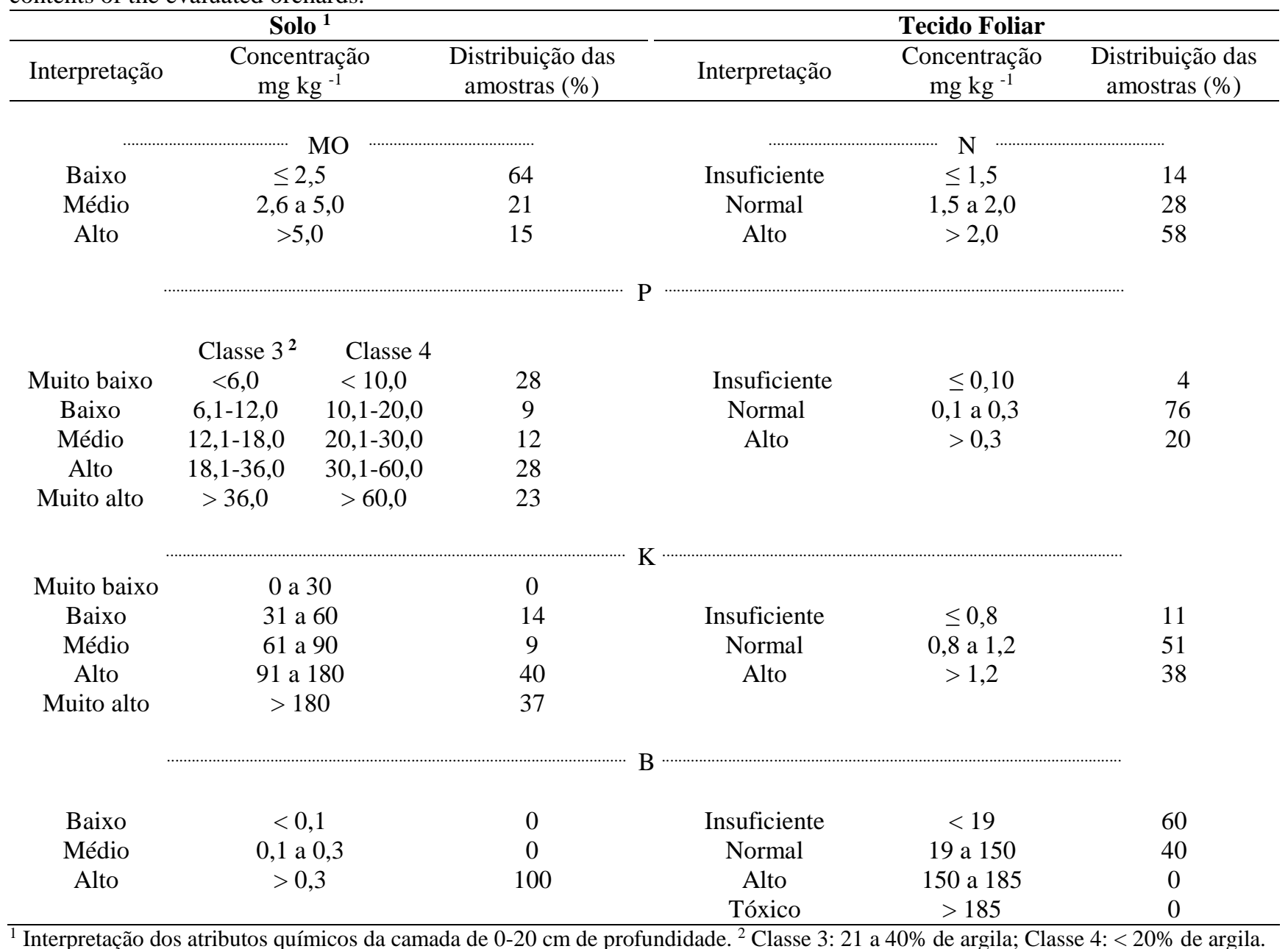

${ }^{1}$ Interpretação dos atributos químicos da camada de 0-20 cm de profundidade. ${ }^{2}$ Classe 3: 21 a $40 \%$ de argila; Classe 4: <20\% de argila.

Fósforo

As concentrações de $\mathrm{P}$ na maioria das amostras de folhas (76 \%) estavam dentro das faixas de concentrações adequadas (>0,10\%). No entanto, no solo, quase metade das amostras (49\%) apresentaram teores de P abaixo do nível crítico indicado. Ou seja, mesmo com níveis teoricamente limitantes de P no solo, as folhas, aparentemente, estavam bem supridas. Nos frutos, o teor de $\mathrm{P}$ apresentou-se próximo $(0,13$ g $\left.100 \mathrm{~g}^{-1} \mathrm{MS}\right)$ a dos estudos de El-Fouly et al.

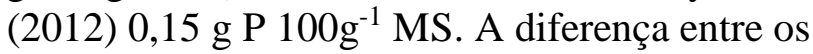
teores de $\mathrm{P}$ no solo e na folha requer mais estudos para ser explicada, porém a capacidade de extração desta espécie pode estar sendo subestimada. Duas possíveis razões parecem ser mais plausíveis para explicar este fato. A primeira é de que, possivelmente, as oliveiras consigam absorver $\mathrm{P}$ moderadamente lábil e não lábil do solo, favorecidas pelo fato de que são plantas perenes e, portanto, podem absorver aos poucos e por longo período este nutriente. Desta forma, ao invés de classificar a oliveira no Grupo 2 - Culturas Exigentes quanto à disponibilidade de P no solo (CQFS-RS/SC, 2016), junto com as frutíferas, talvez a oliveira se comporte mais similar às espécies florestais, enquadradas como Grupo 3 - Culturas Pouco Exigentes. Se as oliveiras fossem enquadradas como pouco exigentes, os teores de $\mathrm{P}$ no solo para cada classe de interpretação seriam a metade dos valores 
apresentados na tabela 3. Neste caso, os pomares avaliados no presente estudo teriam teores de $\mathrm{P}$ com a seguinte distribuição: $23,5,5,17$ e $51 \%$ das amostras do solo enquadradas nas classes de interpretação Muito Baixo, Baixo, Médio, Alto e Muito Alto, respectivamente (CQFS-RS/SC, 2016), totalizando, portanto, $68 \%$ das amostras com níveis Altos e Muito Altos de $\mathrm{P}$ no solo. Esse teor é bem próximo ao encontrado nas folhas (76\%), o que reforça a hipótese de que as oliveiras se comportam de forma mais similar às espécies florestais do que às frutíferas em geral quanto à exigência em $\mathrm{P}$.

A segunda possível explicação remete ao fato de que a camada superficial de solo avaliada no presente estudo é de 0 a $20 \mathrm{~cm}$. Assim, pode ser que os primeiros centímetros da camada mais superficial estejam com sítios de troca saturados em $\mathrm{P}$, fornecendo-o de forma suficiente, porém a concentração é diluída ao amostrar 0 a $20 \mathrm{~cm}$. Como o solo dos pomares não são revolvidos, permite que o $\mathrm{P}$ se concentre nos primeiros centímetros da camada superficial, onde os sítios de adsorção vão sendo gradativamente preenchidos e novas adubações aumentam as formas mais lábeis de $\mathrm{P}$. Primeiramente a adsorção do fósforo ocorre nos sítios mais ávidos e, após, o fósforo excedente é disponível às plantas (RHEINHEIMER et al., 2000b). Sugere-se que trabalhos futuros fracionem mais as camadas de solo amostradas a fim de elucidar se o ajuste do $\mathrm{P}$ passa por uma alteração na camada diagnóstica ou no enquadramento da espécie quanto ao nível de exigência deste nutriente (ou ambos).

Potássio

A grande maioria dos pomares apresentou teores de $\mathrm{K}$ trocável nas amostras de solo acima do nível crítico, bem como teores normais de $\mathrm{K}$ na folha, enquanto que uma minoria exibiu teores baixos no solo (14\%) e na folha (11\%), esses podem ser corrigidos através da adubação (Tabela 5). As plantas que apresentaram os teores normais nas amostras de folha $(51 \%) \mathrm{e}$ solo $(40 \%)$ podem apresentar maior tolerância à pragas e moléstias, aumento da rigidez dos tecidos e, melhores condições que outras oliveiras durante a estiagem, pois este nutriente ajuda no fechamento dos estômatos no momento de alta radiação solar e melhora a eficiência de uso da água (IOC, 2007).

Os pomares cujas amostras de solo apresentaram teores altos de K trocável (37\%; Tabela 5) devem ser monitoradas futuramente, a fim de evitar uma possível inibição competitiva com o $\mathrm{Ca}$ e $\mathrm{Mg}$ na planta pelo excesso de $\mathrm{K}$ (MALAVOLTA et al., 1997). As oliveiras que apresentaram teores altos de $\mathrm{K}$ devem receber menores doses deste nutriente na adubação.

Vale ressaltar que os solos de Caçapava do Sul, em geral, apresentam como material de origem o granito, onde a presença de feldspatos de potássio entre os minerais primários favorece concentrações de K naturalmente maiores do que em outros solos do sul do Brasil. Os feldspatos potássicos, juntamente com as micas, são os principais minerais que tem potencial em fornecer este nutriente, pois são abundantes numa grande variedade de rochas (BORTOLUZZI et al., 2005).

Quando o K se apresenta em níveis baixos, como nas amostras de solo (14\%) e de folha (11\%) (Tabela 5), podem ser comprometidas as atividades enzimáticas e a resistência a doenças reduzidas nas oliveiras, além de diminuir a qualidade dos frutos e, consequentemente, do azeite (VOSSEN, 2007), diminuir a resistência a seca e ao frio (IOC, 2007), como também, reduzir a intensidade e produtividade da floração quando a deficiência de $\mathrm{K}$ for prolongada $\mathrm{e}$ severa (EREL et al., 2013). Os sintomas de deficiência se manifestam mais significativamente nos frutos do que nas folhas, mas a recomendação de adubação se dá sempre quando as análises foliares apresentarem teores insuficientes de K (EPAMIG, 2012). Nos frutos, este nutriente se manifestou acima das quantidades encontradas em azeitonas $(1,28 \mathrm{~g} \mathrm{~K}$ $100 \mathrm{~g}^{-1} \mathrm{MS}$ ) por Rodrigues et al. (2012) e ElFouly et al. (2012), que variaram de 0,02 a 0,68 g K $100 \mathrm{~g}^{-1} \mathrm{MS}$. Por ser um nutriente muito importante para a produção de azeitonas e qualidade do azeite (VOSSEN, 2007), as doses de $\mathrm{K}$ devem sempre estar ajustadas para que não 
ocorram interferências na produção.

Boro

As amostras de solo apresentaram-se $100 \%$ enquadradas na classe Alto quanto ao teor de B. No entanto, mais da metade dos pomares $(60 \%)$ apresentaram nível considerado insuficiente de B nas amostras de folha (Tabela 5), e teores baixos nos frutos. A discrepância entre o teor de $\mathrm{B}$ no solo e na planta requer mais estudos para ser explicada, pois basicamente são três processos que devem ocorrer dentro da planta para que o B desempenhe sua função: a absorção, a translocação (xilema e floema) e a utilização. A eficiência do B na planta depende desses três processos combinados (WANG et al., 2015). No entanto, observando os resultados, pode-se pressupor que: (a) o nível crítico de B no solo não está ajustado à situação de clima e solo do centro-sul do estado; (b) a época e as doses de adubação foliar não estão ajustadas às variedades de oliveira estudadas; (c) as oliveiras podem ter sofrido algum tipo de interferência na absorção de B do solo.

Nos frutos, os teores deste nutriente obtidos por Rodrigues et al. (2012) e El-Fouly et al. (2012) foram maiores (variaram de 9 a $43 \mathrm{mg} \mathrm{B}$ $\left.\mathrm{kg}^{-1} \mathrm{MS}\right)$ dos encontrados no presente estudo (média de 6,69 $\mathrm{mg} \mathrm{B} \mathrm{Kg}^{-1} \mathrm{MS}$ ). Vale ressaltar que quando o teor de B na oliveira é baixo, pode ocorrer baixo pegamento da florada (EPAMIG, 2012), supressão dos pontos de crescimento (raiz, broto, flor e folha jovem) (BROWN et al., 1999), além de afetar os processos metabólicos (WANG et al., 2015), e aumentar a porcentagem de flores imperfeitas e redução dos frutos (PERICA et al., 2001).

Correlação de Pearson entre os nutrientes

Após a interpretação dos teores de nutrientes na planta, realizou-se a correlação de Pearson entre os atributos químicos das amostras de solo $(0$ a $40 \mathrm{~cm})$, folha e fruto, na Tabela 6.

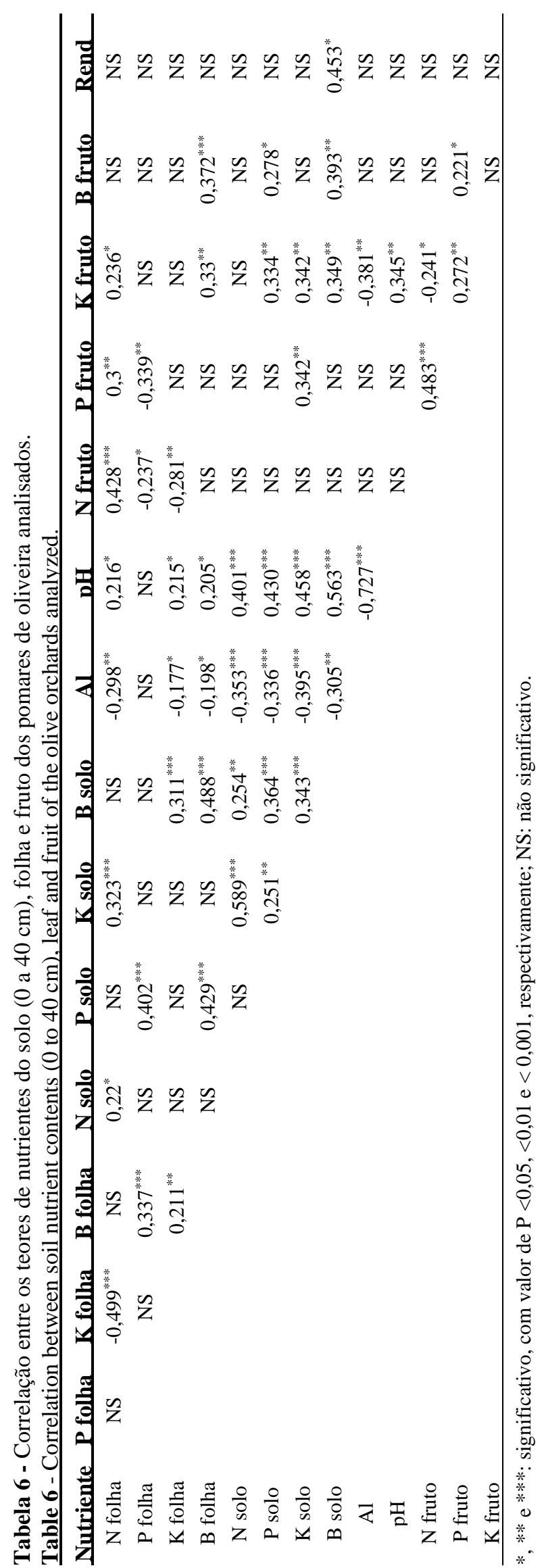


Os resultados revelam que os atributos químicos do solo influenciaram na presença de nutrientes nas folhas e frutos das oliveiras, principalmente $\mathrm{N}, \mathrm{P}$ e $\mathrm{B}$. Entre o $\mathrm{Al}^{3+}$ e os nutrientes $\mathrm{N}, \mathrm{P}, \mathrm{K}$ e $\mathrm{B}$ do solo, verificou-se relações inversas e significativas. Este efeito corrobora com a hipótese anteriormente mencionada de os níveis elevados de $\mathrm{Al}^{3+}$ trocável na camada de $20-40 \mathrm{~cm}$ de profundidade, verificado em alguns pomares (44\% das amostras de $20-40 \mathrm{~cm}$ apresentaram $>1 \mathrm{cmol}_{\mathrm{c}} \mathrm{kg}^{-1} \mathrm{Al}^{3+}$; Tabela 4), estejam limitando o crescimento radicular e a absorção de nutrientes pelas oliveiras. A oliveira é sensível à presença de $\mathrm{Al}^{3+}$ no solo, por isso é recomendado que o pH seja entre 6,0 (EPAMIG, 2012 e 6,5 (CQFS - RS/SC, 2016) para manter o potencial de rendimentos da cultura. A recomendação que consta na última edição do manual de Calagem e Adubação para o Sul do Brasil sugere a correção do solo para oliveira até $30 \mathrm{~cm}$ de profundidade, incorporando o calcário na quantidade equivalente a 1,5 vezes a dose de calcário pelo método SMP para atingir $\mathrm{pH}_{\text {água }}$ 6,5. Desta forma, com $\mathrm{pH}$ 6,5 em toda a camada de 0-30 $\mathrm{cm}$, favoreceria a correção do $\mathrm{pH}$ das camadas subjacentes a valores acima de 5,5, precipitando o Al trocável. No entanto, isto só poderia ser realizado na implantação dos pomares novos. Para pomares adultos, a única alternativa seria de tentar corrigir o pH do subsolo aos poucos, sem revolvimento, conforme anteriormente discutido. Assim, com $\mathrm{pH}$ um pouco mais elevado em superfície, a formação de um gradiente no perfil favoreceria a descida da frente de alcalinização ao longo do tempo (CQFS - RS/SC, 2016).

Ao correlacionar o teor de B nos frutos com os teores de $\mathrm{B}$ no solo e no tecido foliar, verificou-se que a concentração de B no solo parece ser mais importante para a nutrição dos frutos do que o teor foliar deste nutriente (Figura 2).

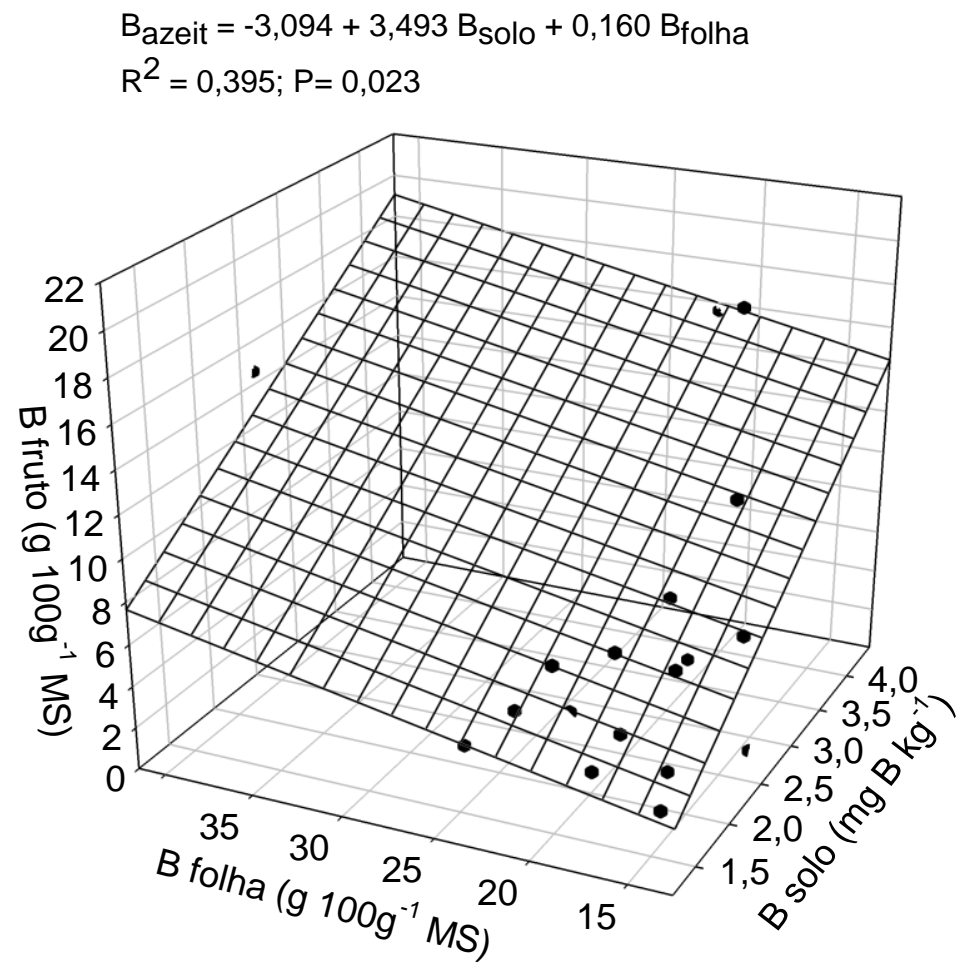

Figura 2 - Correlação entre os teores de B no solo, folha e fruto de oliveiras.

Figure 2 - Correlation between B contents in soil, leaf and fruit of olive trees. 
Entre todos os nutrientes avaliados, o teor de B no solo foi o único atributo a apresentar relação direta e significativa com a produtividade de frutos $\left(\mathrm{R}^{2}=0,453, P=0,0447\right.$; Tabela 6). Vale lembrar, que os teores de B nas folhas e nos frutos foram baixos, enquanto que no solo $100 \%$ das amostras foram ranqueadas na classe alto.

Há duas prováveis explicações para este fato. A primeira delas é de que a absorção de B pela planta (e a sua subsequente translocação na planta) não estejam ocorrendo normalmente, devido a algum motivo desconhecido. Geralmente a eficiência do B se origina do efeito combinado de três processos dentro da planta: absorção, translocação e utilização. A morfologia da raiz e a quantidade de micorrizas podem afetar a efetividade da absorção de $\mathrm{B}$ em oliveiras. Ao longo da translocação de B a partir da raiz, as diferentes concentrações de $B$ na seiva e no exsudato do xilema, além da eficiência do uso da água, podem exercer papéis fundamentais na tolerância à deficiência de $\mathrm{B}$ na planta. Além disso, deve haver a eficiência na retranslocação de $B$ que ocorre no floema. Essa eficiência depende principalmente da extensão e transferência do xilema para o floema e da variedade e quantidade de porções de cis-diol no floema. Outra condição de eficiência no uso de B pela planta é a parede celular, pois ela age como ponte de $\mathrm{B}$ com a membrana plasmática da célula (WANG et al., 2015).

A segunda possível razão é a de que o nível crítico de $\mathrm{B}$ no solo não está ajustado à situação de clima e solo do sul do Brasil, pois, na realidade, os solos podem estar com os teores baixos para a oliveira, o que explicaria os níveis insuficientes nas amostras de folhas e frutos. $\mathrm{O}$ nível crítico de B no solo, calculado no presente estudo para possibilitar que a planta atinja rendimento relativo de $90 \%$ do seu potencial, foi de $1,6 \mathrm{mg} \mathrm{B} \mathrm{kg}^{-1}$ (Figura 3).

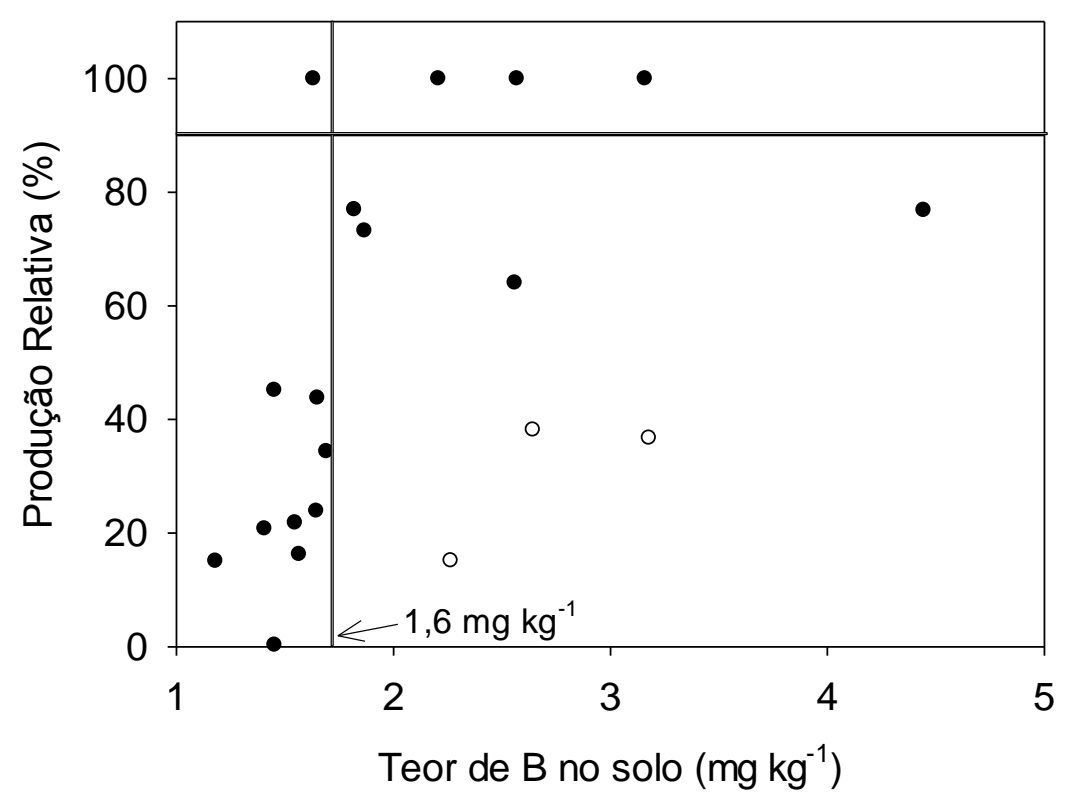

Figura 3 - Relação entre o teor de B no solo e o Rendimento Relativo dos frutos (\%) em pomares de oliveira da região central do RS. Símbolos abertos (círculos em branco) não foram considerados para o ajuste por serem considerados "outliers".

Figure 3 - Relationship between B content in soil and relative yield of fruits (\%) in olive orchard studies in center in the RS. Open symbols (white circles) were not taken into account in the adjust because they were considered outliers. 
Os pontos do gráfico que apresentaram teor de $\mathrm{B}$ no solo maior do que primeiro ponto a apresentar $100 \%$ de rendimento relativo e que proporcionaram um rendimento relativo $\geq 50 \%$ foram desconsiderados para a elaboração no nível crítico. Afinal, é provável que o baixo rendimento relativo de frutos nestas árvores não foi causada nem por escassez nem por excesso de Boro, e que algum outro fator tenha sido o limitante.

O nível crítico de $1,6 \mathrm{mg} \mathrm{B} \mathrm{kg}^{-1}$ é superior ao valor indicado nas bibliografias apresentadas anteriormente, que são as utilizadas pelos olivicultores na manutenção de pomares no estado. No caso do manual de Calagem e Adubação do sul do Brasil (CQFS-RS/SC, 2016), não há discriminação para a oliveira e, portanto, o nível crítico seria o mesmo que para as culturas regulares, que é de $0,3 \mathrm{mg} \mathrm{B} \mathrm{kg}^{-1}$, ou seja, aproximadamente cinco vezes mais baixo do que a encontrada no presente estudo. $\mathrm{Na}$ publicação da EPAMIG (2012), não há citação de nível crítico no solo, limitando-se a sugerir o monitoramento através do teor de $\mathrm{B}$ no tecido foliar. Dentre as frutíferas, em citros, a produção máxima ocorre com $1 \mathrm{mg} \mathrm{B} \mathrm{kg}^{-1}$ (MATOS JR et al., 2009). Os autores chamam a atenção quanto ao teor encontrado, pois é superior ao utilizado na interpretação de análises de solo para culturas anuais. Geralmente, quando a adubação de B é realizada na implantação do pomar, é mais difícil ocorrer a deficiência durante a fase de crescimento da planta, mas caso ocorra, as adubações de crescimento e de produção devem ser realizadas obedecendo os resultados das análises químicas de solo e folha, além das análises visuais e da produtividade dos pomares (COUTINHO et al., 2009). Culturas exigentes em B, como a oliveira, deveriam ser supridas continuamente por toda a vida da planta para que possa desempenhar suas funções no tecido (EPAMIG, 2012).

Considerando a relevância do $\mathrm{B}$ para a produtividade de frutos observada no presente estudo, acredita-se que um grande avanço na nutrição de oliveiras requer necessariamente um ajuste no manejo deste nutriente. No presente estudo, é importante ressaltar que o ano agrícola foi limitante à plena produção de oliveiras devido ao excesso de chuva ocorrida na época de floração e polinização. Futuras pesquisas devem ser conduzidas para i) tentar corroborar ou ajustar o nível crítico deste nutriente no solo em outras condições de solo e clima; e ii) buscar aprimorar a nutrição de $\mathrm{B}$ em flores e frutos testando fontes, doses e épocas de aplicação de fertilizantes minerais e foliares.

\section{Conclusões}

Os solos em geral não apresentaram problemas de acidez na camada superficial. Porém, cerca da metade dos solos apresentaram forte indício de limitação química ao crescimento de raízes devido à presença de $\mathrm{Al}$ trocável em nível potencialmente tóxico em camadas subsuperficiais de solo.

$\mathrm{O}$ teor de nitrogênio se apresentou em excesso nos tecidos foliares em mais da metade dos pomares. De forma geral, o $\mathrm{N}$ foi o único nutriente dentre os avaliados cujo excesso pode estar limitando a produção de oliveiras.

A maior parte dos pomares apresentaram concentrações adequadas de $\mathrm{P}$ e de $\mathrm{K}$ no tecido foliar. No entanto, a interpretação dos teores de $\mathrm{P}$ do solo apontou escassez deste nutriente, o que não condiz com o estado nutricional da planta e sugere necessidade de mais pesquisas.

$\mathrm{O}$ teor de boro do solo foi o parâmetro químico que mais limitou a produtividade de frutos das oliveiras. Os resultados apontam que o nível crítico de $\mathrm{B}$ no solo é $1,6 \mathrm{mg} \mathrm{kg}^{-1}$. Este valor é superior ao valor indicado nas principais bibliografias utilizadas pelos olivicultores para a recomendação de adubação dos pomares no estado.

\section{Agradecimentos}

Os autores agradecem à Associação de Olivicultures de Caçapava do Sul e à empresa Bosque Olivos pela disponibilização dos pomares para avaliação. D.B.B.B. e agradecem à CAPES pela bolsa de mestrado. 


\section{Referências Bibliográficas}

ADAMI, D. Azeites de oliva gaúchos conquistam espaço na mesa de apreciadores. $2017 . \quad$ Disponível em: <http://pioneiro.clicrbs.com.br/rs/cultura-etendencias/noticia/ 20 17/06/azeites-de-olivagauchos-conquistam-espaco-na-mesa-deapreciadores 9823565 .html>. Acesso em: 11 set. 2017.

ALBA, J. M. et al. Zoneamento edafoclimático da olivicultura para o Rio Grande do Sul. CONGRESSO BRASILEIRO DE FRUTICULTURA, 23, 2014, Cuiabá. Anais... Fruticultura: oportunidades e desafios para o Brasil. EMBRAPA, 2014. p. 34.

BENDER, D.D.B.B. Necessidade de ajustes no sistema de recomendação de calagem e adubação de oliveiras (Olea europaea L.) no sul do Brasil. 2018. 87 f. Dissertação (Mestrado em Ciências Biológicas) - Universidade Federal do Pampa, São Gabriel, RS. 2018.

BEUTEL, J. et al. Leaf analysis for California deciduous fruits. In BEUTEL, J; URIU, K; LILLELAND, O. Soil and Plant Tissue Testing in California; University of California, 1983. p.15-17.

BRAGA, G. N. A matéria orgânica do solo. 2010. Disponível em: < http://agronomiacomgismonti.blogspot.com.br/ 2010/07/materia-organica-do-solo.html >. Acesso em: 12 de nov. de 2017.

BROWN, P.H.; HU, H. Phloem mobility of boron is species dependent: Evidence for phloem mobility in sorbitolrich species. Annals of Botanic, v. 77, p. 497-505, 1996.

BORTOLUZZI, E. C.; POLETO, C. Alterações na mineralogia de um Argissolo do Rio Grande do Sul submetido à fertilização potássica. Revista Brasileira de Ciência do Solo, Viçosa, v. 29, n.3, p. 327-335, 2005.
CANTARUTTI et al. Avaliação da fertilidade do solo e recomendação de fertilizantes. In: CANTARUTTI, R. B.; BARROS, N. F. DE; MARTINEZ, H. E.; NOVAIS, R. F. Fertilidade do solo. Viçosa: UFV, 2007. p. 769-850.

CHAPMAN, H. D. Diagnostic Criteria for Plants and Soils. University of California, 1966. 136-141 p.

CHILDERS, N.F. Fruit Nutrition. Horticultural Publications, Rutgers University, New Jersey/EUA, 1966. 888 p.

CliMATE-DATA. Clima: Cachoeira do Sul. Disponível em: <https://pt.climatedata.org/location/ 33791/>. Acesso em: 11 set. 2017.

Climate-DATA. Clima: Caçapava do Sul. Disponível em: <https://pt.climatedata.org/location/ 43790/>. Acesso em: 11 set. 2017.

COUTINHO, E. F.; RIBEIRO, F. C.; CAPPELlARO, T. H. Sistemas de produção. Cultivo de Oliveira (Olea europaea L.). EMBRAPA Clima Temperado. Pelotas, RS, 2009. $125 \mathrm{p}$.

CQFS - RS/SC - Comissão de Química e Fertilidade do Solo - RS/SC. Manual de Calagem e Adubação para os estados do Rio Grande do Sul e Santa Catarina. Porto Alegre, 2016. 375 p.

EL-FOULY et al. Nutrient Removal from different parts of Koroneiki Olive Trees Grown in Sandy Soil as a Base of Fertilizer Recommendation in Egypt. British Journal of Applied Science \& Tecnology, v. 4, n. 11, p. 1120, 2012.

EPAMIG - Empresa de Pesquisa Agropecuária de Minas Gerais. Oliveira no Brasil: tecnologias de produção. Minas Gerais, 2012, 406 p. 
EREL et al. The importance of olive (Olea europaea L.) tree nutritional status on its productivity. Scientia Horticulturae, v 159, p. 8-18, 2013.

FERNÁNDEZ-ESCOBAR et al. El cultivo del olivo. Fertilización. 6 ${ }^{\mathrm{a}}$ ed. In: FERNÁNDEZESCOBAR, R.; BARRANCO, D. Madri: Mundi-Prensa, 2008. p. 297-362.

FERNÁNDEZ-ESCOBAR, R. et al. Long-term effects of $\mathrm{N}$ fertilization on cropping and growth of olive trees and on $\mathrm{N}$ accumulation in soil profile. European Journal of Agronomy, v. 31, n. 4, p. 223-232, 2009.

FREEMAN et al. Diagnosing and correcting nutrient problems. In: FREEMAN, M.; URIU, K.; HARTMANN, H. T. Olive Production Manual. University of California, Agriculture and Natural Resources, Oakland, 2005. p. 83-92.

IOC - INTERNATIONAL OLIVE OIL COUNCIL. Olive. 2010 Madrid, ESP. Disponível em: <http://www.internationaloliveoil.org>. Acesso em: 24 out. 2017.

MALAVOLTA, E. et al. Avaliação do estado nutricional das plantas: princípios e aplicações. In: MALAVOLTA, E.; VITTI, G. C.; OLIVEIRA, S. A. Piracicaba: POTAFÓS, 1997. p. 319.

MATOS JR. et al. Fruteiras Tropicais do Brasil: citros. In: MATOS JR, D. DE M; QUAGGIO, J. A.; CANTARELLA, H. EMBRAPA Agroindústria Tropical, n. 18, p. 70-88, 2009.

OLIVA - Associação Brasileira de produtores, importadores e Comerciantes de azeite de oliva. Conhecendo melhor o azeite de oliva História e Origem do Azeite. Disponível em: <http://www. oliva.org.br/conhecendo-oazeite.php>. Acesso em: 14 mai. 2016.

PAULUS, E. A avaliação do crescimento inicial de oliveira "Arbequina" em diferentes manejos do solo e dosagens de fósforo. 2011. 83 f. Dissertação (Mestrado em Ciência do Solo) - Universidade Federal de Santa Maria, Santa Maria/RS. 2011.

PERICA et al. Foliar boron application improves flower fertility and fruit set in olive. HortScience, v. 36, p 714-716, 2001.

REIS, C. et al. Modification of procedure for extraction of boron in soils. Recie, v. 15, p. 9194, 2006.

RHEINHEIMER, D.S. et al. Alterações de atributos do solo pela calagem superficial e incorporada a partir de pastagem natural. Revista Brasileira de Ciência do Solo, v. 24, p. 797-805, 2000a.

RHEINHEIMER, D.S. et al. Depleção do fósforo inorgânico de diferentes frações provocada pela extração sucessiva com resina em diferentes solos e manejos. Revista Brasileira de Ciência do Solo, v. 24, n. 2, p. 345-354, 2000b.

RODRIGUES, M. A. et al. Fertilizer recommendations for olive based upon nutrients removed in crop and pruning. Scientia Horticulturae, v. 142, n. 13, p. 205-211, 2012.

SEMA - SECRETARIA MUNICIPAL DO MEIO AMBIENTE; UFSM UNIVERSIDADE FEDERAL DE SANTA MARIA. Inventário Florestal Contínuo do Rio Grande do Sul. Porto Alegre/RS; 2003. Disponível em: <http://coralx.ufsm.br/ifcrs /clima.htm>. Acesso em: 20 out. 2017.

SIBCS - SISTEMA BRASILEIRO DE CLASSIFICAÇÃO DE SOLOS. Empresa Brasileira de Pesquisa Agropecuária EMBRAPA Solos. $4^{\mathrm{a}}$ edição. Brasília/DF, 2014. $342 \mathrm{p}$.

SILVA et al. Estudo Mineral de uma supercalagem no milho. In: IX ENCONTRO LATINO AMERICANO DE INICIAÇÃO 
CIENTÍFICA E V ENCONTRO LATINO AMERICANO DE PÓS-GRADUAÇÃO UNIVERSIDADE DO VALE DO PARAÍ-BA, 2006, Vale do Paraíba. Anais... Vale do Paraíba, RJ, 2006. p 551-553.

SILVA, T. M. Caracterização da estrutura da cadeia produtiva da olivicultura no estado do Rio Grande do Sul: o caso das propriedades rurais de Cachoeira do Sul. 2013. 76 f. TCC (Trabalho de Conclusão de Curso) - UFRGS, Faculdade de Ciências Econômicas, Porto Alegre/RS. 2013.

TEDESCO et al. Análise de solo, plantas e outros materiais. Porto Alegre/RS, UFRGS. Boletim técnico $\mathrm{n}^{\mathrm{o}} 5$, $2^{\mathrm{a}}$ edição revisada e ampliada, 1995. $174 \mathrm{p}$.

VOSSEN, P. Organic Olive Production Manual. University of California. Agriculture and Natural Resources Communication Services. Oakland, California, 2007. 105 p.

WANG et al. Boron deficiency in woody plants: various responses and tole-rance mechanisms. Frontiers in Plant Science, 2015. Disponível em: <https: //www.ncbi.nlm.nih.gov/pmc/articles/PMC462 1400/>. Acesso em: 27 ago. 2017.

WRB - WORLD REFERENCE BASE FOR SOIL RESOURCES: A framework for international classification, correlation and communication. Food and Agriculture Organization of the United Nations. Rome, IUSS/ISRIC/FAO, 2006. 145 p. 